\title{
Genetic testing for susceptibility to breast and ovarian cancer: Evaluating the impact of a direct-to-consumer marketing campaign on physicians' knowledge and practices
}

Melanie F. Myers, $\mathrm{PhD}, \mathrm{MS}^{1}$, Man-Huei Chang, $M P H^{1}$, Cynthia Jorgensen, $\mathrm{PhD}^{2}$, William Whitworth, $M P H^{1}$, Sidibe Kassim, $M D^{3}$, James A. Litch, MD, DTMH ${ }^{3}$, Lori Armstrong, PhD ${ }^{4}$, Barbara Bernhardt, $M S^{5}$, W. Andrew Faucett, $M S^{6}$, Debra Irwin, PhD, $M S P H^{7}$, Judy Mouchawar, MD, MSPH ${ }^{8}$, and Linda A. Bradley, $P h D^{1}$

\begin{abstract}
Purpose: To assess the impact of direct-to-consumer marketing of genetic testing for risk of breast and ovarian cancer by a biotechnology company on: 1) physicians' knowledge; 2) reasons given when asking questions about the test; and 3) physicians' practice patterns in two pilot cities where the campaign took place and two control cities. Methods: Survey of randomly selected family physicians, internists, obstetrician-gynecologists, and oncologists from May 1-May 21, 2003. Results: Physicians' knowledge did not differ between pilot and control cities. Significant differences (pilot versus control cities) were seen in the reasons patients gave for asking questions about testing. More physicians in pilot cities (14\%) than control cities (7\%) reported an increase in the number of times they ordered genetic testing for breast and ovarian cancer risk in the previous 6 months (adjusted odds ratio $1.9,95 \%$ confidence interval, 1.2-3.1). Awareness of professional guidelines and being in a practice with a policy on genetic testing for risk of breast and ovarian cancer were associated with physicians' behaviors and interest among patients in testing. Conclusions: Given the complexity and limitations of genetic testing for risk of breast and ovarian cancer, the development and broad dissemination of clinical guidelines and education of physicians are needed. Genet Med 2006:8(6):361-370.
\end{abstract}

Key Words: direct-to-consumer, advertising, BRCA, breast cancer, ovarian cancer

In the United States, the probability of a women developing invasive breast cancer from birth to death is estimated at 1 in 7 $(13.4 \%)$ and 1 in $58(1.7 \%)$ for ovarian cancer. ${ }^{1,2}$ An estimated $5-10 \%$ of breast cancer cases are associated with an autosomal dominant pattern of inheritance. ${ }^{3}$ Mutations in the BRCA1 and BRCA2 (BReast CAncer) genes are associated with a predisposition to develop breast and ovarian cancer (BOC). Women identified with BRCA1 or BRCA2 (BRCA) mutation face lifetime risks of $36-85 \%$ for breast cancer and $16-60 \%$ for ovarian cancer, depending on the population studied. ${ }^{2}$

\footnotetext{
From the ${ }^{1}$ Office of Genomics and Disease Prevention, Centers for Disease Control and Prevention, Atlanta, GA; ${ }^{2}$ Division of Cancer Prevention and Control, Centers for Disease Control and Prevention, Altanta, GA; ${ }^{3}$ Epidemiology Program Office, Centers for Disease Control and Prevention, Atlanta, GA; ${ }^{4}$ Division of Tuberculosis Elimination, Centers for Disease Control and Prevention, Atlanta, GA; ${ }^{5}$ Department of Medicine, University of Pennsylvania School of Medicine, Philadelphia, PA; ${ }^{6}$ Public Health Practice and Program Office, Centers for Disease Control and Prevention, Atlanta, GA; ${ }^{7}$ Department of Epidemiology, School of Public Health, University of North Carolina-Chapel Hill, Chapel Hill, NC; ${ }^{8}$ Clinical Research Unit, Kaiser Permanente Colorado, Denver, CO.

Melanie F. Myers, PhD, MS, University of Cincinnati and Cincinnati Children's Hospital Medical Center, ML 4006, 3333 Burnet Ave., Cincinnati, OH, 45229.

Submitted for publication December 21, 2005.

Accepted for publication February 9, 2006.
}

DOI: 10.1097/01.gim.0000223544.68475.6c
Genetic testing for BRCA1 and BRCA2 mutations, which has been available since 1994 and 1995, respectively, ${ }^{3,4}$ allows highrisk persons to be identified before they have developed BOC. Test results may predict risk more accurately than family history alone, and may provide additional information on which to base decisions about screening and medical management. Thousands of mutations and variations in BRCA have been described, ${ }^{5}$ and gene sequencing is often necessary. Because of patent restrictions, full gene sequencing for clinical purposes can only be performed in one laboratory in the U.S. ${ }^{6}$ This laboratory offers three options for testing: 1) full DNA sequencing, including detection of five specific large genomic rearrangements of the $B R C A 1$ gene; 2) targeted DNA sequence analysis for a specified mutation in a BRCA gene once a family mutation is known; or 3) DNA sequence analysis of specific portions of the $B R C A$ genes designed to detect three mutations that occur more commonly in people of Ashkenazi Jewish descent. $^{7}$

If an unaffected person at increased risk for BOC based on family history wants to pursue testing to learn whether she or he (in the case of breast cancer) carries a BRCA mutation, a family member with cancer is generally tested first. If a mutation is identified in that person, unaffected blood relatives can then be tested for the familial mutation to help predict their 
risk. Identification of a mutation in an unaffected person does not necessarily mean she or he will develop cancer. Results of testing could also reveal a gene change that is interpreted as a variant of unknown significance. For these mutations, it is unclear whether the variant is a normal polymorphism or is associated with an increased risk for cancer. Such variants may be found in up to $13 \%$ of persons tested. ${ }^{8}$

In the United States, guidelines for providers and expert opinions on counseling and testing for genetic susceptibility to BOC have been developed by several professional organizations. ${ }^{9-12}$ The guidelines do not have a standard definition of a "positive" family history for BOC, but they agree that testing for $B R C A$ mutations is most appropriate for women who have a family history of early-onset BOC, and they do not recommend it for women in the general population. More recently, the U.S. Preventive Services Task Force also recommended against routine testing for women whose family history does not reveal an increased risk for a BRCA mutation. The USPSTF also recommended that women whose family history is associated with an increased risk for deleterious mutations in $B R C A$ genes be referred for genetic counseling and evaluation for testing. ${ }^{13}$ The ultimate goal of testing is to reduce morbidity and mortality associated with inherited BOC through increased surveillance, chemoprevention, or prophylactic mastectomy or oophorectomy.

In September, 2002, the biotechnology company that holds the patent for DNA-based sequencing for inherited susceptibility to BOC (and is thus the major provider in the US) began a pilot campaign for marketing its test (BRACAnalysis ${ }^{\circledR}$ ) directly to consumers in Atlanta, GA, and Denver, CO (the pilot cities). Although direct-to-consumer advertising (DTCA) of pharmaceuticals has been employed for over two decades, ${ }^{14}$ and advertising of genetic tests is becoming more common on the Internet, ${ }^{15}$ this was the first time a biotechnology company marketed a genetic test directly to consumers through mass media. This pilot direct-to-consumer (DTC) campaign targeted women aged $25-54$ years and their physicians. The stated intent was to raise awareness among women with a personal or family history of BOC and motivate them to speak to their health care providers about their personal risk for hereditary BOC and how BRACAnalysis ${ }^{\circledR}$ could assess their risk and guide them to effective options for medical management. ${ }^{16}$

Pre-campaign efforts by the company included outreach and education for physicians; in August, 2002, physicians in the pilot cities were sent a launch mailer to inform them about the campaign along with support materials for identifying and managing patients. In addition, the company coordinated the launch of the pilot campaign with clinical programs for assessing cancer risk in Atlanta and Denver by holding meetings with providers of cancer care and community cancer groups to promote awareness of the campaign before it began. The company also created a new website with self-directed patient triage and tools for collecting family history and offered this along with a dedicated, toll-free telephone number. Finally, the company conducted a five-month advertising campaign including TV, radio, and print ads about $B R C A$ testing. ${ }^{16}$
To assess the impact of the DTC campaign on the knowledge, attitudes and behaviors of physicians and consumers relative to genetic testing for susceptibility to BOC, two population-based surveys were conducted during the four months post-campaign. Findings from the survey of physicians are presented in this article.

\section{METHODS}

At the request of state epidemiologists and public health officials in the two pilot cities as well as two control cities, the Centers for Disease Control and Prevention (CDC) assisted in an investigation to assess the impact of the DTC campaign. The comparison (control) cities (Seattle, WA, and RaleighDurham, NC) were selected based on their general proximity to the pilot cities and the presence of public health staff that could be quickly mobilized to participate in the investigation.

Institutional review board approval was obtained from the CDC and the four state health departments involved in the investigation. Office of Management and Budget Clearance was covered under \#0920-008 for Epi-Aids. Participation was voluntary and consent was implied if the survey was completed and returned. The objectives of the investigation were to assess: 1) physicians' knowledge regarding genetic testing for susceptibility to BOC; 2) reasons patients give for asking questions about genetic testing for BOC; and 3) physicians' practice patterns and reported interest of their patients in genetic testing for susceptibility to BOC. Providers in both pilot and comparison cities were surveyed.

\section{Study population and design}

A sample of 2,000 physicians from three specialties (family medicine, internal medicine, and obstetrics-gynecology) was randomly selected from the American Medical Association (AMA) Physician Masterfile to be proportionally representative of the number of physicians practicing in those specialties within each city. In addition, because of their small numbers, all 262 medical, surgical, and gynecological oncologists who were practicing in the 4 cities were selected. In addition to specialty, selection criteria, as indicated in the Masterfile, included spending more than 20 hours per week in direct patient care. From this sample of 2,262 physicians, confirmation of addresses was attempted by up to three telephone calls. Based on these calls, 469 physicians were deemed ineligible (26 were retired, 205 were not known or no longer at that address, 42 refused to participate, 58 did not treat cancer, 81 were not available during the survey period, and 57 could not receive express mail at a post office box). From the eligible pool of 1,793 physicians, 1,600 were randomly selected to receive the survey. The survey instrument was developed by a nine-member working group that included experts in content, public health officials, and epidemiologists from the four states, ORC Macro (a consulting company), and CDC. The 35 questions in the survey covered the demographics of the physician and the practice, the physician's knowledge about inherited susceptibility to BOC, reports of questions from patients, referral and 
practice patterns, and the physician's desire to learn more about genetic testing for susceptibility to BOC. The surveys were pilot tested with a convenience sample of physicians $(\mathrm{N}=4)$ to assess the clarity of the questions.

The survey and a $\$ 50$ money order were sent to the 1,600 physicians by express mail on May 1, 2003. Reminder postcards were sent a week later, and calls were made and faxes sent to remind non-responding physicians two weeks after the initial mailing. A duplicate express mailing was sent to physicians who had still not returned the survey three weeks after the initial mailing.

\section{Statistical methods}

All analyses were performed using $\mathrm{SAS}^{\circledR}$ software for Windows, v8.02 (SAS Inc., Cary, NC).

Data on nine characteristics of physicians were compared between pilot and control cities. Chi-square testing at a significance level of 0.05 was used to determine the differences in proportions between groups. Multivariate logistic regression analysis was performed using the hierarchical backwards elimination method. ${ }^{17,18}$ Odds ratios (OR) with $95 \%$ confidence intervals (CI) were calculated to compare pilot and control cities on the relationship between various physician characteristics and responses to the survey. All covariates (Table 1) and two-factor interaction terms for main effect variables (pilot versus control cities and the primary specialty of the physician) were included in the multivariate analysis. Tests of the contribution of covariates were conducted by dropping the least significant variable in the model based on the Wald $\chi^{2}$ and maximum likelihood estimation value at $P \leq 0.05$ until all remaining variables were significant.

Characteristics of physicians assessed in the study (Table 1) included specialty (family medicine, internal medicine, obstetrics/gynecology, or oncology) and practice setting (collapsed into four settings: group practice, solo practice, hospital/academic, or managed care. Managed care included respondents who indicated they practiced in a staff model health maintenance organization (HMO), a managed care organization, or other model HMO), sex, and hours worked in direct patient care per week $(<20,20-40$, and $\geq 40)$. Although a selection criterion was working 20 hours or more per week, we chose to trichotomize the variable due to the large percentage of respondents who reported working $<20$ hours. The survey also asked about years in practice since residency $(>20,11-20$, and $\leq 10$ ), a family or personal history of BOC, awareness of national professional guidelines, practice policies on offering the testing, and geographical area of practice ("metro," which included central city and suburban, and "rural," which included small city/town and rural).

The three questions on the physicians' knowledge of genetic testing for BOC (Table 2) were adapted from a previous survey. ${ }^{19}$ For $\chi^{2}$ analysis and logistic regression, the responses to knowledge questions were dichotomized as "correct" or "not correct" ("not sure" was considered "not correct"). To further assess factors associated with the knowledge of physicians in logistic regression analysis, a new knowledge variable was created and responses were dichotomized into $2-3$ and $0-1$ correct responses (Table 3 ).

In assessing the interest of patients in genetic testing for susceptibility to BOC (as reported by physicians) and the practice patterns of physicians in this area, responses of "not applicable" (Table 4) were excluded to avoid unstable estimates. For responses on awareness of professional guidelines and having a policy about genetic testing for risk of BOC, "not sure" was combined with "no." Only interaction terms and variables that were significantly associated with being in a pilot city (a proxy for exposure to the campaign) or physician specialty were left in the final models.

\section{RESULTS}

In all, 1,070 surveys (67\%) were returned. Eighteen were excluded from the analysis because respondents said they did not see patients (16) or were retired (2). A total of 1,052 (66\%) questionnaires were analyzed. Although we had selected physicians from the AMA Physician Masterfile who were listed there as spending more than 20 hours per week in direct patient care, $8 \%$ of respondents said they worked fewer than 20 hours per week.

Sixty-five percent of respondents were men, 53\% were members of a group practice (single- or multi-specialty), and $58 \%$ had been in practice more than 10 years. Most physicians worked in a metro area, but in Raleigh-Durham, the majority worked in a rural setting. Overall, 35\% of physicians were aware of professional guidelines, and $10 \%$ said their practice had a specific policy on genetic testing for BOC risk (Table 1).

\section{Receipt of educational materials}

Thirty-two percent of physicians in the pilot cities and 13\% in the control cities (results not shown) reported receiving educational materials from a company promoting genetic tests for risk of BOC in the 12 months preceding the survey $(\mathrm{N}=$ $221, P<0.01)$. Most $(75 \%)$ of those who reported receiving this information said they got it by mail. Fifty-two physicians (24\% of those who reported receiving information) said they remembered the name of the company from which they received information, and 45 of these correctly reported the name of the company when requested by the questionnaire. Forty percent of those who received information reported it was useful to their practice.

\section{Knowledge}

Although more physicians in the pilot cities reported receiving educational materials, as previously reported, ${ }^{20}$ no differences by city status (pilot, control) were seen by $\chi^{2}$ analysis in the percentage of correct responses to the three questions on knowledge of genetic testing for BOC. Significant differences $(P<0.01)$ were seen by specialty, however, for each of the knowledge questions (Table 2). Logistic regression analysis found interaction between city status (pilot versus control) and specialty; specifically, obstetrician-gynecologists (ob/ gyns) in the pilot cities were more likely than ob/gyns in the 
Table 1

Characteristics of physicians and variables used in regression models

\begin{tabular}{|c|c|c|c|c|}
\hline & \multicolumn{2}{|c|}{ Pilot cities $(\mathrm{N}=561)$} & \multicolumn{2}{|c|}{ Control cities $(\mathrm{N}=491)$} \\
\hline & $\begin{array}{c}\text { Denver } \\
(\mathrm{N}=270) \\
\text { No. }(\%)\end{array}$ & $\begin{array}{c}\text { Atlanta } \\
(\mathrm{N}=291) \\
\text { No. }(\%)\end{array}$ & $\begin{array}{c}\text { Seattle } \\
(\mathrm{N}=328) \\
\text { No. }(\%)\end{array}$ & $\begin{array}{c}\text { Raleigh } \\
(\mathrm{N}=163) \\
\text { No. }(\%)\end{array}$ \\
\hline \multicolumn{5}{|l|}{ Specialty } \\
\hline Oncology & $34(13)$ & $24(8)$ & $41(13)$ & $14(9)$ \\
\hline Obstetrics and gynecology & $55(20)$ & $98(34)$ & $53(16)$ & $35(21)$ \\
\hline Internal medicine & $70(26)$ & $97(33)$ & $97(30)$ & $57(35)$ \\
\hline Family medicine & $111(41)$ & $72(25)$ & $137(42)$ & $57(35)$ \\
\hline \multicolumn{5}{|l|}{ Setting } \\
\hline Group practice $^{a}$ & $153(56)$ & $167(57)$ & $160(50)$ & $82(51)$ \\
\hline Solo practice & $36(13)$ & $72(25)$ & $50(15)$ & $28(17)$ \\
\hline Hospital/academic ${ }^{b}$ & $49(18)$ & $45(15)$ & $82(25)$ & $51(31)$ \\
\hline Managed care & $32(12)$ & $7(2)$ & $31(10)$ & $1(1)$ \\
\hline \multicolumn{5}{|l|}{ Sex } \\
\hline Female & $93(35)$ & $94(33)$ & $120(37)$ & $54(33)$ \\
\hline Male & $175(65)$ & $195(67)$ & $207(63)$ & $109(67)$ \\
\hline \multicolumn{5}{|l|}{ Hours worked/week } \\
\hline$>40$ & $104(39)$ & $142(50)$ & $82(26)$ & $66(41)$ \\
\hline $20-40$ & $145(55)$ & $125(44)$ & $199(63)$ & $76(47)$ \\
\hline$<20$ & $17(6)$ & $17(6)$ & $36(11)$ & $19(12)$ \\
\hline \multicolumn{5}{|c|}{ Years in practice since residency } \\
\hline$>20$ & $85(32)$ & $59(20)$ & $85(26)$ & $37(23)$ \\
\hline $11-20$ & $84(31)$ & $99(34)$ & $115(35)$ & $43(27)$ \\
\hline$\leq 10$ & $100(37)$ & $132(46)$ & $126(39)$ & $82(51)$ \\
\hline \multicolumn{5}{|c|}{ Family history of breast or ovarian cancer ${ }^{c}$} \\
\hline Yes & $65(25)$ & $69(24)$ & $88(28)$ & $31(19)$ \\
\hline No & $198(75)$ & $220(76)$ & $230(72)$ & $132(81)$ \\
\hline \multicolumn{5}{|c|}{$\begin{array}{l}\text { Aware of any national professional guidelines to determine } \\
\text { appropriate patients for testing }\end{array}$} \\
\hline Yes & $107(41)$ & $101(37)$ & $115(35)$ & $50(32)$ \\
\hline No & $84(32)$ & $115(42)$ & $119(37)$ & $65(41)$ \\
\hline Not sure & $70(27)$ & $60(22)$ & $90(28)$ & $43(27)$ \\
\hline \multicolumn{5}{|c|}{$\begin{array}{l}\text { Practice has a specific policy regarding genetic testing for } \\
\text { risk of breast and ovarian cancer }\end{array}$} \\
\hline Yes & $43(16)$ & $26(9)$ & $31(9)$ & $8(5)$ \\
\hline No & $214(81)$ & $247(88)$ & $275(84)$ & $147(91)$ \\
\hline Not sure & $7(3)$ & $9(3)$ & $21(6)$ & $6(4)$ \\
\hline \multicolumn{5}{|l|}{ Area of principal practice } \\
\hline Metro & $203(75)$ & $231(79)$ & $246(75)$ & $62(38)$ \\
\hline Rural & $67(25)$ & $60(21)$ & $80(25)$ & $100(62)$ \\
\hline
\end{tabular}

Missing values are excluded. Percentages may not add to 100 due to rounding.

${ }^{a}$ Group practice includes single-specialty and multi-specialty group practices.

${ }^{b}$ Hospital/academic includes hospital/medical or community health clinic/public health agency/Veterans Administration or military hospital.

${ }^{c}$ Family history includes a diagnosis of breast or ovarian cancer in an immediate blood relative, a spouse or significant other, or the respondent. 
Table 2

Physicians' knowledge of genetic testing for susceptibility to breast and ovarian cancer, by specialty

\begin{tabular}{|c|c|c|c|c|c|}
\hline & & Specialty & & & \\
\hline $\begin{array}{r}\text { How likely is a wo } \\
\text { inherited a } B \\
\text { who gets bre }\end{array}$ & & & & & \\
\hline Not sure & $63(17)$ & $49(16)$ & $21(9)$ & $1(1)$ & \\
\hline Women can inhe & & & & & \\
\hline Either parent ${ }^{c}$ & $129(35)$ & $132(42)$ & $169(71)$ & $101(91)$ & $<0.01$ \\
\hline $25 \%$ & $81(22)$ & $77(24)$ & $71(30)$ & $23(21)$ & $<0.01$ \\
\hline $50 \%{ }^{c}$ & $152(41)$ & $133(42)$ & $113(48)$ & $76(68)$ & \\
\hline $75 \%$ & $12(3)$ & $5(2)$ & $2(1)$ & $1(1)$ & \\
\hline Not sure & $121(33)$ & $99(31)$ & $49(21)$ & $11(10)$ & \\
\hline
\end{tabular}

Missing values excluded. Percentages may not add to 100 due to rounding.

${ }^{a}$ From $2 \times 4$ table (specialty $\times$ correct or incorrect responses), "Not sure" counted as incorrect.

${ }^{b}$ Data for 5 respondents who replied "less likely" not shown.

${ }^{c}$ Correct response.

${ }^{d}$ Data for 1 respondent who replied "father only" not shown.

"Data for 4 respondents who replied "100\%" not shown.

control cities to answer knowledge questions correctly (Table 3). We also found that being aware of professional guidelines was associated with getting more knowledge questions correct. Finally, being in solo practice (versus managed care) and being in practice 11 years or more (versus $\leq 10$ years) were inversely associated with getting 2-3 knowledge questions correct (Table 3).

\section{Desire for more knowledge}

Sixty-eight percent $(\mathrm{N}=707)$ of physician respondents ( $71 \%$ of family physicians, $64 \%$ of internists, $75 \%$ of ob/gyns, and $59 \%$ of oncologists) reported an increased need or desire to learn more about cancer genetics or genetic testing for risk of BOC in the last six months (versus the same time period a year before). This report (data not shown) contrasted with the $1 \%$ of physicians who reported a decrease in their need to learn more (8\% responded "not applicable" and 23\% responded "remained the same").

\section{Rationales for questions of patients}

Physicians were asked the reasons their patients gave for asking questions about genetic testing for risk of BOC during the previous six months. When "not sure" responses were excluded, $31 \%$ of physicians in pilot cities and $25 \%$ in control cities reported that having had breast or ovarian cancer was a reason patients gave for asking questions about this testing $(P=0.05), 62 \%$ of physicians in pilot and $55 \%$ in control cities reported that having a family member with 1 of these cancers was a reason $(P=0.02)$. In other findings, the results were $27 \%$ (pilot) versus $8 \%$ (control) for reporting as a reason that patients had seen an ad promoting genetic testing for risk of BOC in the popular media $(P<0.01)$ and $22 \%$ versus $14 \%$ for saying that patients asked questions because they wanted information about available medical options if a BRCA mutation was identified $(P<0.01)$.

These differences remained in logistic regression analyses that adjusted for other variables, but we found interactions with city (pilot versus control) in several of the models. For example, among physicians who practiced in rural areas, those in pilot cities were more likely than those in control cities to report having a family member with BOC as a reason for patients' questions (adjusted OR (AOR), 2.1, 95\% CI, 1.2-3.5), but this finding did not hold up for metro physicians (AOR, $0.8,95 \% \mathrm{CI}, 0.5-1.1)$. In addition, among female physicians, those in pilot cities were more likely than their counterparts in control cities to report that seeing or hearing an advertisement promoting genetic testing for BOC risk was a reason for patients' questions (AOR, 2.7, 95\% CI, 1.2-6.2). The association 
Table 3

Characteristics of physicians by odds of answering 2-3 knowledge questions correctly

\begin{tabular}{lc}
\hline Variable & $\begin{array}{c}\text { Adjusted OR } \\
(95 \% \mathrm{CI})\end{array}$ \\
\hline Specialty $\times$ city & \\
Oncology & $0.7(0.2-2.7)$ \\
$\quad$ Pilot (vs. control) & \\
Ob/Gyn & $2.8(1.4-5.3)$ \\
Pilot (vs. control) & \\
Internal medicine & $0.6(0.4-1.0)$ \\
Pilot (vs. control) & \\
Family medicine & $1.0(0.6-1.5)$ \\
Pilot (vs. control) & \\
Setting & $0.9(0.5-1.6)$ \\
Group practice & \\
Solo practice & $0.5(0.3-0.9)$ \\
Hospital/academic & \\
Managed care & $0.9(0.5-1.6)$
\end{tabular}

Years in practice since residency

$\begin{array}{lc}>20 & 0.6(0.4-0.9) \\ 11-20 & 0.7(0.5-0.9) \\ \leq 10 & \text { Reference }\end{array}$

Aware of professional guidelines

Yes (vs. no/not sure)

$2.4(1.8-3.4)$

CI, confidence interval; OR, odds ratio.

Missing values are excluded. Odds ratios are calculated as the likelihood of getting 2-3 questions right vs. 0 or 1 questions.

${ }^{a}$ Group practice includes single-specialty and multi-specialty group practices. ${ }^{b}$ Hospital/academic includes hospital/medical or community health clinic/ public health agency/Veterans Administration or military hospital.

with pilot cities was even stronger in this instance for male physicians (AOR, 6.6, 95\% CI, 2.8-15.6). Finally, physicians in pilot cities were more likely than those in control cities to report that wanting information about available medical options if a $B R C A$ mutation is identified was a reason patients gave for asking questions (AOR, 1.6, 95\% CI, 1.1-2.3).

\section{Change in patient interest and physician practice}

We asked five questions to learn more about how patient interest and the practices of physicians had changed over time (Table 4). We previously reported ${ }^{20}$ that physicians in pilot cities were more likely than those in control cities to report increased interest among patients in genetic testing for BOC risk (in the six months before the survey versus the same period one year earlier). These increases were in questions asked, requests for referrals to genetic counseling, and requests for testing. In addition, physicians in the pilot cities (14\%) were more likely than those in control cities (7\%) to report an increase in directly ordering genetic tests for risk of BOC, but there was no statistical difference between cities (pilot versus control) in the number of physicians reporting an increase in referrals to a genetics or oncology center. ${ }^{20}$

In logistic regression, the four variables most consistently associated with increased patient interest (more questions asked, more requests for referrals and testing) and increases in directly ordering the genetic test or referring to genetics or oncology were pilot city, specialty, awareness of professional guidelines, and having a policy on the testing (Table 5). Two variables - awareness of professional guidelines and having a policy - were positively associated with all five increases. Being in a pilot city was positively associated with four of the increases. Being an oncologist or ob/gyn (versus family physician) was also positively associated with four of the increases and interacted with sex in the other model.

\section{DISCUSSION}

The public health implications of this DTC campaign are wide-ranging. Although the campaign was piloted in only two cities, it represents population-based marketing of a test that is not considered appropriate for the majority of the population. From the public health perspective, potential benefits of the campaign include increased awareness and knowledge among consumers and physicians about inherited susceptibility to $B O C$ and genetic testing for mutations in the BRCA genes. This might, in turn, lead to more appropriate referrals for $B R C A$ testing by physicians, more appropriate uptake of genetic testing and cancer screening, possible reduction of anxiety among women who had previously over-estimated their BOC risk, and, depending on medical management decisions, early detection or prevention of BOC among some women with a family history.

Potential risks of the campaign include insufficient knowledge about inherited susceptibility to BOC and testing for $B R C A$, which could lead to inappropriate referrals, uptake, decisions, and interpretation of the test, and increased alarm and anxiety about the risk of developing BOC among consumers. In addition, screening (e.g., with mammography) might be foregone and women falsely reassured if they are tested and found not to carry a mutation in a BRCA gene. Finally, physicians and the health care system as a whole might be overtaxed through increased requests for testing, and resources might not be available to provide appropriate education, counseling, and follow-up among those persons who are interested in $B R C A$ testing.

Findings from this investigation suggest an association between the DTCA of genetic testing for BOC risk and an increase in patient interest about the test (based on the reports of physicians) as well as an increase in the number of tests ordered by physicians. Our finding that physicians in pilot cities were more likely to report receiving the educational materials presumably reflects their being targeted by the biotechnology company conducting the campaign. We also found that physicians in pilot cities were more likely to report certain reasons that patients gave to explain their asking questions about testing (an affected family member, seeing an ad, wanting infor- 
Table 4

Patient interest and physician practices, last six months versus same time period one year earlier

\begin{tabular}{|c|c|c|c|c|}
\hline & \multicolumn{2}{|c|}{ Pilot cities $(\mathrm{N}=561)$} & \multicolumn{2}{|c|}{ Control cities $(\mathrm{N}=491)$} \\
\hline & $\begin{array}{l}\text { Denver } \\
(\mathrm{N}=270) \\
\text { No. }(\%)\end{array}$ & $\begin{array}{l}\text { Atlanta } \\
(\mathrm{N}=291) \\
\text { No. }(\%)\end{array}$ & $\begin{array}{l}\text { Seattle } \\
(\mathrm{N}=328) \\
\text { No. }(\%)\end{array}$ & $\begin{array}{l}\text { Raleigh } \\
(\mathrm{N}=163) \\
\text { No. }(\%)\end{array}$ \\
\hline \multicolumn{5}{|c|}{$\begin{array}{l}\text { The number of patients asking about genetic testing for breast and ovarian } \\
\text { cancer risk has }\end{array}$} \\
\hline Increased & $96(36)$ & $96(34)$ & $63(19)$ & $30(19)$ \\
\hline Remained the same & $128(48)$ & $143(51)$ & $207(64)$ & $102(64)$ \\
\hline Decreased & $8(3)$ & $5(2)$ & $6(2)$ & $2(1)$ \\
\hline Not applicable & $33(12)$ & $36(13)$ & $50(15)$ & $26(16)$ \\
\hline \multicolumn{5}{|c|}{$\begin{array}{c}\text { The number of patients asking directly for a referral for genetic counseling } \\
\text { and possible genetic testing for breast and ovarian cancer risk has }\end{array}$} \\
\hline Increased & $57(22)$ & $42(15)$ & $36(11)$ & $14(9)$ \\
\hline Remained the same & $166(63)$ & $189(68)$ & $233(71)$ & $111(70)$ \\
\hline Decreased & $5(2)$ & $7(3)$ & $7(2)$ & $4(3)$ \\
\hline Not applicable & $37(14)$ & $42(15)$ & $51(16)$ & $30(19)$ \\
\hline \multicolumn{5}{|c|}{$\begin{array}{l}\text { The number of patients asking directly for genetic testing for breast and } \\
\text { ovarian cancer risk has }\end{array}$} \\
\hline Increased & $72(27)$ & $59(21)$ & $40(12)$ & $18(11)$ \\
\hline Remained the same & $151(57)$ & $173(62)$ & $230(70)$ & $108(68)$ \\
\hline Decreased & $8(3)$ & $5(2)$ & $7(2)$ & $4(3)$ \\
\hline Not applicable & $33(13)$ & $42(15)$ & $50(15)$ & $28(18)$ \\
\hline \multicolumn{5}{|c|}{$\begin{array}{l}\text { The number of times you refer patients to a genetics or oncology center } \\
\text { for assessment of risk for breast/ovarian cancer and possible genetic } \\
\text { testing has }\end{array}$} \\
\hline Increased & $75(28)$ & $66(23)$ & $77(24)$ & $31(20)$ \\
\hline Remained the same & $148(56)$ & $170(61)$ & $200(61)$ & $97(61)$ \\
\hline Decreased & $4(2)$ & $5(2)$ & $3(1)$ & $2(1)$ \\
\hline Not applicable & $38(14)$ & $40(14)$ & $47(14)$ & $29(18)$ \\
\hline \multicolumn{5}{|c|}{$\begin{array}{l}\text { The number of times you directly order genetic testing for breast and } \\
\text { ovarian cancer risk has }{ }^{a}\end{array}$} \\
\hline Increased & $35(13)$ & $41(15)$ & $22(7)$ & $10(6)$ \\
\hline Remained the same & $165(62)$ & $174(62)$ & $210(65)$ & $100(63)$ \\
\hline Decreased & $7(3)$ & $7(2)$ & $4(1)$ & $2(1)$ \\
\hline Not applicable & $58(22)$ & $59(21)$ & $87(27)$ & $46(29)$ \\
\hline
\end{tabular}

Missing values are excluded.

"Increased includes responses of "significantly and slightly increased" and decreased includes "slightly and significantly decreased."

mation about management options if a BRCA mutation was identified). However, the lack of knowledge among physicians about BRCA testing (Table 2) raises concerns that many physicians are not prepared to deal with the increased demand that can be generated by DTCA of genetic tests.

A study conducted concurrently by Kaiser Permanente Colorado on the impact of the same campaign within two managed care organizations - one in a city where the campaign occurred and one in a city where it did not - found a significant increase in referrals attributed to the DTC campaign. ${ }^{21}$ We did not, however, find physicians in pilot cities reporting a greater increase in referrals to genetics or oncology centers when compared to control cities. Still, we found a trend (albeit statistically insignificant) for female physicians in pilot cities to report a greater increase in referrals made than their counterparts in control cities. We also found that oncologists and ob/ gyns were more likely to report an increase in referrals made than family physicians. Regardless of specialty, physicians who were aware of professional guidelines or who had a policy on testing (a setting similar to Kaiser Permanente Colorado) were more likely to report increases in referrals made than those not aware of the guidelines or not having a policy, respectively. 


\section{Myers et al.}

Table 5

Results of regression analyses to predict patient interest and physician practices

Patients asking about testing increased Adjusted OR (95\% CI)

City

Pilot (vs. control)

$2.1(1.6-2.9)$

Specialty

Oncology

$2.9(1.7-4.8)$

$\mathrm{Ob} / \mathrm{Gyn}$

$2.1(1.4-3.1)$

Internal medicine

$1.3(0.9-2.0)$

Family medicine

Reference

Sex

Female (vs. male)

$1.4(1.0-1.9)$

Aware of Professional Guidelines

Yes (vs. no/not Sure)

$1.5(1.1-2.0)$

Practice has a policy

Yes (vs. no/not sure)

$2.0(1.3-3.3)$

Patients asking for referral increased Adjusted OR (95\% CI)

City

Pilot (vs. control)

$1.6(1.1-2.4)$

Specialty

Oncology

$3.5(1.9-6.4)$

$\mathrm{Ob} / \mathrm{Gyn}$

$2.6(1.5-4.4)$

Internal medicine

$1.3(0.7-2.3)$

Family medicine

Reference

Aware of professional guidelines

Yes (vs. no/not sure)

$1.8(1.2-2.7)$

Practice has a policy

Yes (vs. no/not Sure)

$3.3(2.0-5.5)$

Patients asking directly for testing increased Adjusted OR (95\% CI)

City

Pilot (vs. control)

$2.1(1.5-3.0)$

Sex $\times$ specialty

Female

Oncology

$1.5(0.6-4.2)$

$\mathrm{Ob} / \mathrm{Gyn}$

$0.6(0.3-1.1)$

Internal medicine

$0.8(0.4-1.7)$

Family medicine

Reference

Male

Oncology

$3.4(1.7-7.0)$

$\mathrm{Ob} / \mathrm{Gyn}$

$3.1(1.6-5.8)$
Table 5

Continued

\begin{tabular}{cc}
\hline & $\begin{array}{c}\text { Patients asking directly } \\
\text { for testing increased } \\
\text { Adjusted OR (95\% CI) }\end{array}$ \\
\hline Internal medicine & $1.7(0.9-3.4)$ \\
Family medicine & Reference \\
Aware of professional guidelines & \\
Yes (vs. no/not sure) & $1.5(1.1-2.2)$ \\
Practice has a policy & \\
Yes (vs. no/not sure) & $2.7(1.6-4.4)$ \\
& $\begin{array}{c}\text { Physician has increased } \\
\text { number of referrals } \\
\text { Adjusted OR (95\% CI) }\end{array}$ \\
\hline
\end{tabular}

Sex $\times$ city

Female

Pilot (vs. control)

$1.6(0.9-2.6)$

Male

Pilot (vs. control)

$0.8(0.5-1.2)$

Specialty

Oncology

$2.8(1.7-4.7)$

$\mathrm{Ob} / \mathrm{Gyn}$

$2.8(1.9-4.3)$

Internal medicine

$1.4(0.9-2.2)$

Family medicine

Reference

Aware of professional guidelines

Yes (vs. no/not sure)

$1.8(1.3-2.5)$

Practice has a policy

Yes (vs. no/not sure)

$1.7(1.1-2.7)$

Direct orders of test by physician have increased Adjusted OR (95\% CI)

City

Pilot (vs. control)

$1.9(1.2-3.1)$

Specialty

Oncology

$6.4(3.1-13.1)$

$\mathrm{Ob} / \mathrm{Gyn}$

$3.0(1.6-5.7)$

Internal medicine

$2.2(1.1-4.3)$

Family medicine

Reference

Aware of professional guidelines

Yes (vs. no/not sure)

$2.4(1.5-3.8)$

Practice has a policy

Yes (vs. no/not sure)

$1.8(1.0-3.3)$

CI, confidence interval; OR, odds ratio.

Missing values and "not applicable" responses are excluded.

"Increased" includes "slightly" and "significantly increased." "Not increased" includes "remained same," "slightly decreased," and "significantly decreased." 
Mouchawar et al..$^{21}$ also reported (in the Kaiser Permanente Colorado study) a decrease in the proportion of women referred who had a $10 \%$ or greater pre-test probability of carrying a $B R C A$ mutation during the time the campaign took place but concluded that the majority of these referrals were still appropriate. They did not find an increase in testing among women with less than a $10 \%$ pretest probability for a mutation. We found that physicians in the pilot cities were more likely than those in control cities to report an increase in the number of tests they ordered, but we cannot comment on the appropriateness of this testing because this information was not collected. In addition, oncologists, ob/gyns, and internists were all more likely than family physicians to report an increase in tests ordered, as were physicians who were aware of professional guidelines or had a policy on testing (versus those with no guidelines or with no policy).

Our study is not the first to suggest that physicians have limited knowledge about genetic testing for cancer. ${ }^{19,22,23}$ As expected, we found that physicians who were aware of professional guidelines were more knowledgeable than those who were not aware of those guidelines. This finding suggests that one of the most effective ways to influence the knowledge and behavior of physicians is to issue and disseminate professional guidelines. The recent publication of the USPSTF guidelines on genetic risk assessment and BRCA mutation testing for breast and ovarian cancer susceptibility provide evidencebased recommendations on which professional guidelines can be based. ${ }^{13}$ The majority of physicians indicated a desire to learn more about genetic testing for BOC, suggesting that it would be relevant and timely to provide information about inherited susceptibility to cancer. Such education could also help promote adherence to clinical guidelines.

Pharmaceutical companies are spending an increasing amount on DTCA of prescription drugs, ${ }^{24}$ a practice that has proven to be an effective way to communicate the availability of treatment to the public while affecting both physician practice and consumer behavior. For example, studies have shown that physicians feel pressure from patients to prescribe namebrand medications and to order prescription drugs despite their ambivalence about the choice of medications. ${ }^{25,26}$ Physicians are often required to help patients interpret the information presented by advertisers, resulting in lengthened clinical encounters. ${ }^{27}$ Consumer surveys conducted by the Food and Drug Administration and other organizations from 1998-2002 have shown that DTCA of pharmaceuticals increases awareness of medical conditions and disease treatments and influences consumers to ask physicians for particular prescriptions and information about drugs..$^{28,29}$

The impact of DTCA on genetic tests and services on physician practice and consumer behavior may be similar to that seen with pharmaceuticals. For example, physicians may be more likely to make a referral based on a patient's interest in a genetic evaluation, and considerations of appropriateness may become less important. ${ }^{30,31}$ Advertisements may also be an important factor in physicians' decisions to recommend genetic testing for inherited susceptibility to cancer. ${ }^{32}$
Although there are many similarities to prescription drug advertising, the implications of DTCA of genetic testing pose additional challenges. Some of these challenges include limited federal oversight of genetic testing as well as advertisements for genetic testing, difficulty in interpreting genetic tests that are probabilistic in nature, possible oversimplification of complex test results, limited awareness and knowledge of available genetic testing and services, lack of evidence that genetic tests ought to be offered routinely to the general public, and many ethical, legal and social issues involved with the use of genetic information for medical use (such as privacy and confidentiality and potential discrimination in insurance). ${ }^{33,34}$

This study is subject to several limitations. All data are selfreported and we were not able to determine the appropriateness of tests ordered by physicians or validate physician practice patterns with medical records. We asked physicians to report on reasons patients gave for asking questions about genetic testing for breast or ovarian cancer risk. However, direct patient report of reasons for asking about testing could differ from those reported by physicians. We do not have information on demographic or practice information of non-responders and thus are unable to determine if any response-biases exist. Finally, the cross-sectional design of this study prohibits drawing causal associations.

Despite these limitations, identified clinical needs based on the findings from our study include the additional development and dissemination of evidence-based professional guidelines and education of physicians to ensure the appropriate use of $B R C A$ testing. Once developed, additional efforts are needed to promote adherence to guidelines. From a public health perspective, more tracking and monitoring of utilization rates of genetic tests to understand who is using genetic testing and how, and more outcomes research on the benefits of testing performed in clinical, rather than research settings, are needed.

\section{ACKNOWLEDGMENTS}

This study was funded by the Division of Cancer Prevention and Control, Centers for Disease Control and Prevention, Atlanta, GA.

We thank ORC Macro, and the four health departments: The Georgia Department of Human Resources, Division of Public Health; the Colorado Department of Public Health and Environment; the North Carolina Department of Health and Human Services, Division of Public Health; and the Washington State Department of Health for support of this study. We thank Peter L. Taylor, MBA, Senior Editor at Palladian Partners for assistance with technical editing, Shuma R. Panse, MPH and Jennifer Singh, MPH for assistance with early drafts of the manuscript, and Quanhe Yang, PhD for statistical input.

\section{References}

1. American Cancer Society. Cancer Facts \& Figures 2005. Available at: http://www. cancer.org/downloads/STT/CAFF2005f4PWSecured.pdf. Accessed on: February 8, 2006.

2. American Cancer Society. Cancer Reference Information, Overview: Ovarian Cancer. Available at: http://www.cancer.org/docroot/CRI/CRI_2_1x.asp?dt=33. Accessed on: February 8, 2006. 


\section{Myers et al.}

3. Miki Y, Swensen J, Shattuck-Eidens D, Futreal PA, et al. A strong candidate for the breast and ovarian cancer susceptibility gene BRCA1. Science 1994;266:66-71.

4. Wooster R, Bignell G, Lancaster J, Swift S, et al. Identification of the breast cancer susceptibility gene BRCA2. Nature 1995;378:789-792.

5. Division of Intramural Research, National Human Genome Research Institute. Breast Cancer Information Core: an open access on-line breast cancer mutation data base. Available at: http://research.nhgri.nih.gov/bic/. Accessed on: March $17,2005$.

6. Haddow JE, Palomaki GE. ACCE: a model process for evaluating data on emerging genetic tests. In: Khoury MJ, Little J, Burke W (eds). Human Genome Epidemiology. New York, NY: Oxford University Press; 2004;217-233.

7. Myriad Genetic Laboratories, Inc. BRACAnalysis ${ }^{\circledR}$ Technical Specifications. Available at: http://www.myriadtests.com/provider/doc/tech_specs_brac.pdf. Accessed on: October 21, 2005.

8. Frank TS, Deffenbaugh AM, Reid JE, Hulick M, et al. Clinical characteristics of individuals with germline mutations in BRCA1 and BRCA2: analysis of 10,000 individuals. J Clin Oncol 2002;20:1480-1490.

9. American Society of Clinical Oncology. American Society of Clinical Oncology policy statement update: genetic testing for cancer susceptibility. J Clin Oncol 2003;21: 2397-2406.

10. American College of Medical Genetics. Genetic susceptibility to breast and ovarian cancer: assessment, counseling and testing guidelines. Bethesda, Md: American College of Medical Genetics; 1999. Available at: http://www.health.state.ny.us/nysdoh/ cancer/obcancer/contents.htm. Accessed on: October 21, 2005.

11. American College of Obstetricians and Gynecologists. Breast-ovarian cancer screening. ACOG Committee Opinion \#239. Washington, DC: American College of Obstetricians and Gynecologists; 2000.

12. National Comprehensive Cancer Network. Genetics/familial high-risk assessment: breast and ovarian. Available at: http://www.nccn.org/professionals/physician_gls/ PDF/genetics_screening.pdf. Accessed on: September 19, 2005.

13. US Preventive Services Task Force. Genetic risk assessment and BRCA mutation testing for breast and ovarian cancer susceptibility: recommendation statement. Ann Intern Med 2005;143:355-361.

14. Huang AJ. The rise of direct-to-consumer advertising of prescription drugs in the United States. JAMA 2000;284:2240.

15. Gollust SE, Wilfond BS, Hull SC. Direct-to-consumer sales of genetic services on the Internet. Genet Med 2003;5:332-337.

16. Myriad Genetic Laboratories, Inc. Consumer awareness campaign for BRACAnalysis ${ }^{\circledR}$ in Atlanta and Denver, 2002. Salt Lake City, UT: Myriad Genetic Laboratories, Inc.; 2002.

17. Kleinbaum DG, Kupper LL, Morgenstern HM. Epidemiologic Research: Principles and Quantitative Methods. New York: Wiley; 1982.

18. Kleinbaum DG. Epidemiologic methods: the "art" in the state of the art. J Clin Epidemiol 2002;55:1196-1200.
19. Doksum T, Bernhardt BA, Holtzman NA. Does knowledge about the genetics of breast cancer differ between nongeneticist physicians who do or do not discuss or order BRCA testing? Genet Med 2003;5:99-105.

20. Centers for Disease Control and Prevention. Genetic testing for breast and ovarian cancer susceptibility: Evaluating direct-to-consumer marketing - Atlanta, Denver, Raleigh-Durham, and Seattle, 2003. Morb Mortal Wkly Rep 2004;53:603-606.

21. Mouchawar J, Hensley-Alford S, Laurion S, Ellis J, et al. Impact of direct-to-consumer advertising for hereditary breast cancer testing on genetic services at a managed care organization: a naturally-occurring experiment. Genet Med 2005;7:191197.

22. Wideroff L, Vadaparampil ST, Greene MH, Taplin S, et al. Hereditary breast/ovarian and colorectal cancer genetics knowledge in a national sample of US physicians. J Med Genet 2005;42:749-755.

23. Freedman AN, Wideroff L, Olson L, Davis W, et al. US physicians' attitudes toward genetic testing for cancer susceptibility. Am J Med Genet 2003;120:63-71.

24. Rosenthal MB, Berndt ER, Donohue JM, Frank RG, et al. Promotion of prescription drugs to consumers. N Engl J Med 2002;346:498-505.

25. Mintzes B, Barer ML, Kravitz RL, Bassett K, et al. How does direct-to-consume advertising (DTCA) affect prescribing? A survey in primary care environments with and without legal DTCA. CMAJ 2003;169:405-412.

26. Schwarz RK, Soummerai SB, Avorn J. Physician motivations for nonscientific drug prescribing. Soc Sci Med 1989;28:577-582.

27. Robinson AR, Hohmann KB, Rifkin JI, Topp D, et al. Direct-to-consumer pharmaceutical advertising: Physician and public opinion and potential effects on the physician-patient relationship. Arch Intern Med 2004;164:427-432.

28. US Food and Drug Administration, Center for Drug Evaluation and Research, Office of Medical Policy, Division of Drug Marketing, Advertising, and Communications. Attitudes and behaviors associated with direct-to-consumer (DTC) promotion of prescription drugs: preliminary survey results. Available at: http://www.fda. gov/cder/ddmac/dtctitle.htm. Accessed on: June 19, 2005.

29. Bell RA, Kravitz RL, Wilkes MS. Direct-to-consumer prescription drug advertising and the public. J Gen Intern Med 1999;14:651-657.

30. Hayflick SJ, Eiff MP, Carpenter L, Steinberger J. Primary care physicians' utilization and perceptions of genetics services. Genet Med 1998;1:13-21.

31. Wideroff L, Freedman AN, Olson L, Klabunde CN, et al. Physician use of genetic testing for cancer susceptibility: results of a national survey. Cancer Epidemiol Biomarkers Prev 2003;12:295-303.

32. Vadaparampil ST, Wideroff L, Olson L, Viswanath K, et al. Physican exposure to and attitudes toward advertisements for genetic tests for inherited cancer susceptibility. Am J Med Genet 2005;135:41-46.

33. Gollust SE, Hull SC, Wilfond BS. Limitations of direct-to-consumer advertising for clinical genetic testing. JAMA 2002;288:1762-1767.

34. Gray S, Olopade OI. Direct-to-consumer marketing of genetic tests for cancer: buyer beware. J Clin Oncol 2003;21:3191-3193. 